\title{
Analysis of children's future map drawings in Sapporo City
}

\author{
Akio SHIINO $^{\text {a }}$ \\ ${ }^{a}$ Sapporo City University, a.shiino@scu.ac.jp
}

Keywords: Children, Future map drawings, Natural elements

\section{Abstract:}

This paper aimed at measuring children's idealized future map drawings of urban and natural surroundings in their neighbourhood, analyzing their drawings in local area. As a result of this study, 3,368 elements were extracted out from children's drawings, and multivariate analysis revealed that children's drawings could classify into four types, according to those elements as analysis values. Moreover, natural elements were drawn not only "Nature-oriented" type drawings but also "Urban-oriented" type drawings, even if many of latter cases were recognized as background elements in urban area.

\section{Study background and purpose}

According to The National Biodiversity Strategy of Japan $2012-2020^{1}$, it is pointed out that there are increasing numbers of children who have no knowledge of how to live with nature and adults who cannot teach children how to live with nature, because there are only small areas of vegetated land with low biodiversity in their living environments, especially in urban areas. Based on this consideration, creating a lot of chances of studying and experiencing the attractiveness of nature is an urgent issue for children living in urban areas. Although Sapporo City in Hokkaido, located in the north part of Japan, is a city with a population of more than 1.9 million people, there are a lot of rich nature such as forests and rivers close to urban area, and sometimes several kinds of wildlife can be seen in their daily living.

This paper aimed at analyzing children's future map drawings in local area and clarifying the elements of their "ideal life" in the future. Teine ward, located in the north part of Sapporo City, has a unique annual project calling for future map drawings of Teine, targeting the children at the age of 10 years old (see Figure 1,2). In this study, 526 drawing works by children were analyzed, and 3,368 elements were extracted from these future map drawings.

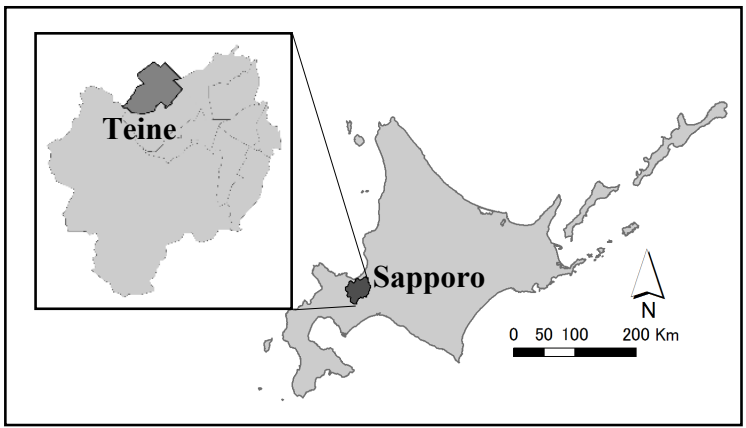

Figure 1. Location of survey area
In addition, principal component analysis and cluster analysis were applied to these elements.

\section{Results}

Counting and classifying the drawing elements, seven nature elements and eight urban elements were extracted as frequently appeared. And principal component analysis was applied using these elements as values. Moreover, gender element was also added as a value of the analysis, for the purpose of clarifying the differences of drawings among children's gender. As a result, gender differences were clarified in drawings, such as male children tend to prefer urban elements, such as road, high-rise buildings or stores, while female children tend to prefer natural elements, such as flowers, birds or forests (see Figure 3). Besides, cluster analysis was applied using sample scores of factor 1 and factor 2, and types of children's future map drawings were classified into four, such as Type I: "Male, Nature-oriented", Type II:

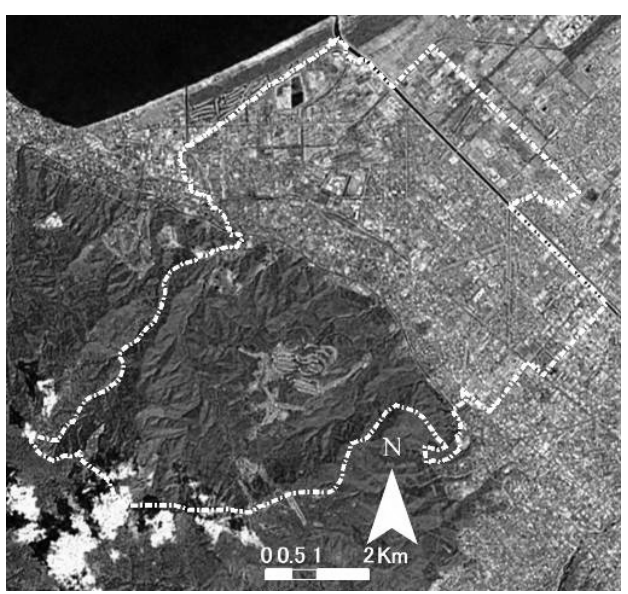

Figure 2. Air photo of Teine district 
"Female, Nature-oriented", Type III: "Male, Urbanoriented" and Type IV: "Female, Urban-oriented" (see Figure 4). Several unique future map drawings were shown in Figure 5. Moreover, gender differences were clarified comparing male children drawings (Type I, III) with female children drawings (Type II, IV), in that female children's drawings showed various generation people, while male children's drawing showed little. On the other hand, orientation differences were shown comparing nature-oriented drawings (Type I, II) with urban-oriented drawings (Type III, IV). In drawings of nature-oriented types, natural elements such as mountains, rivers, flowers or wildlife were numerously drawn. Furthermore, people living with nature were also drawn, such as fishing in the river or watching stars in nature.
Survey area in this study included both urban area and nature area (see Figure 2), and it was guessed that children draw these pictures may often had relationships with nature in their daily living. Besides, even if urban elements such as high-rise buildings or trains were drawn in urban-oriented types, natural elements, such as forests or mountains, were also drawn as background landscape. Considering these results, it was guessed that children drawn these pictures might potentially regarded nature as important symbols of their hometown.

\section{References}

Ministry of the Environment, The National Biodiversity Strategy of Japan 2012-2020,

https://www.env.go.jp/press/files/en/528.pdf

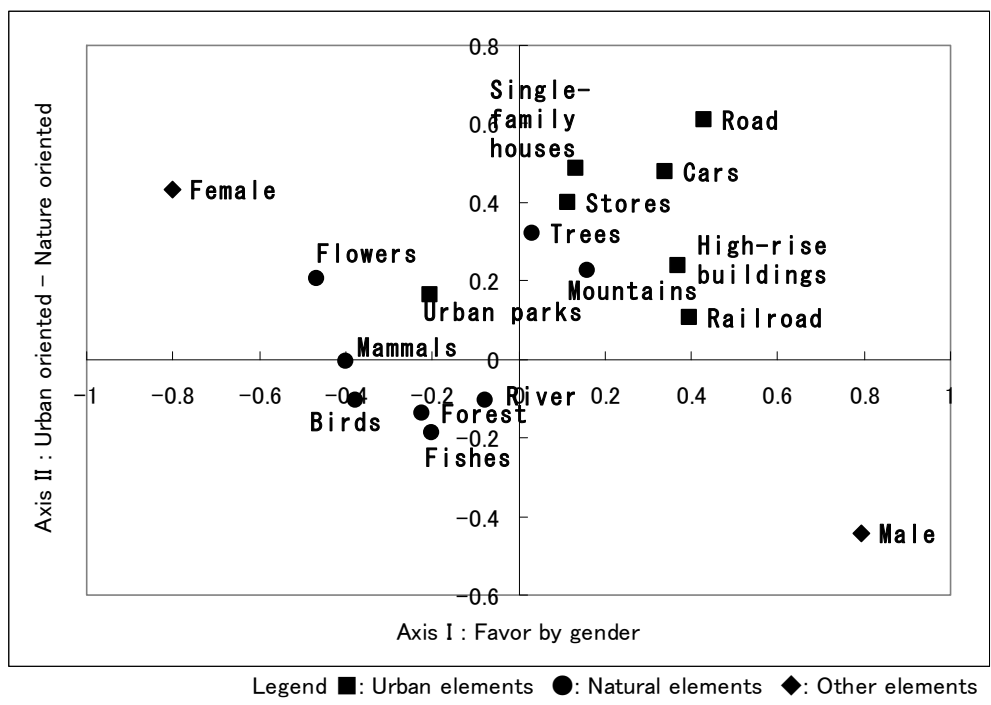

Figure 3. Scatter chart of principal component loading

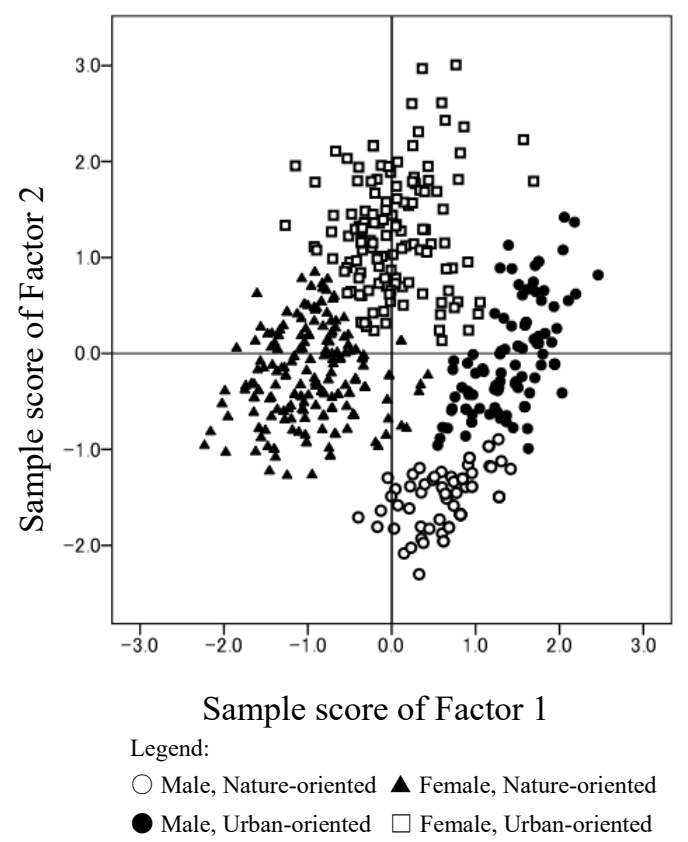

Figure 4. Scatter chart of sample score

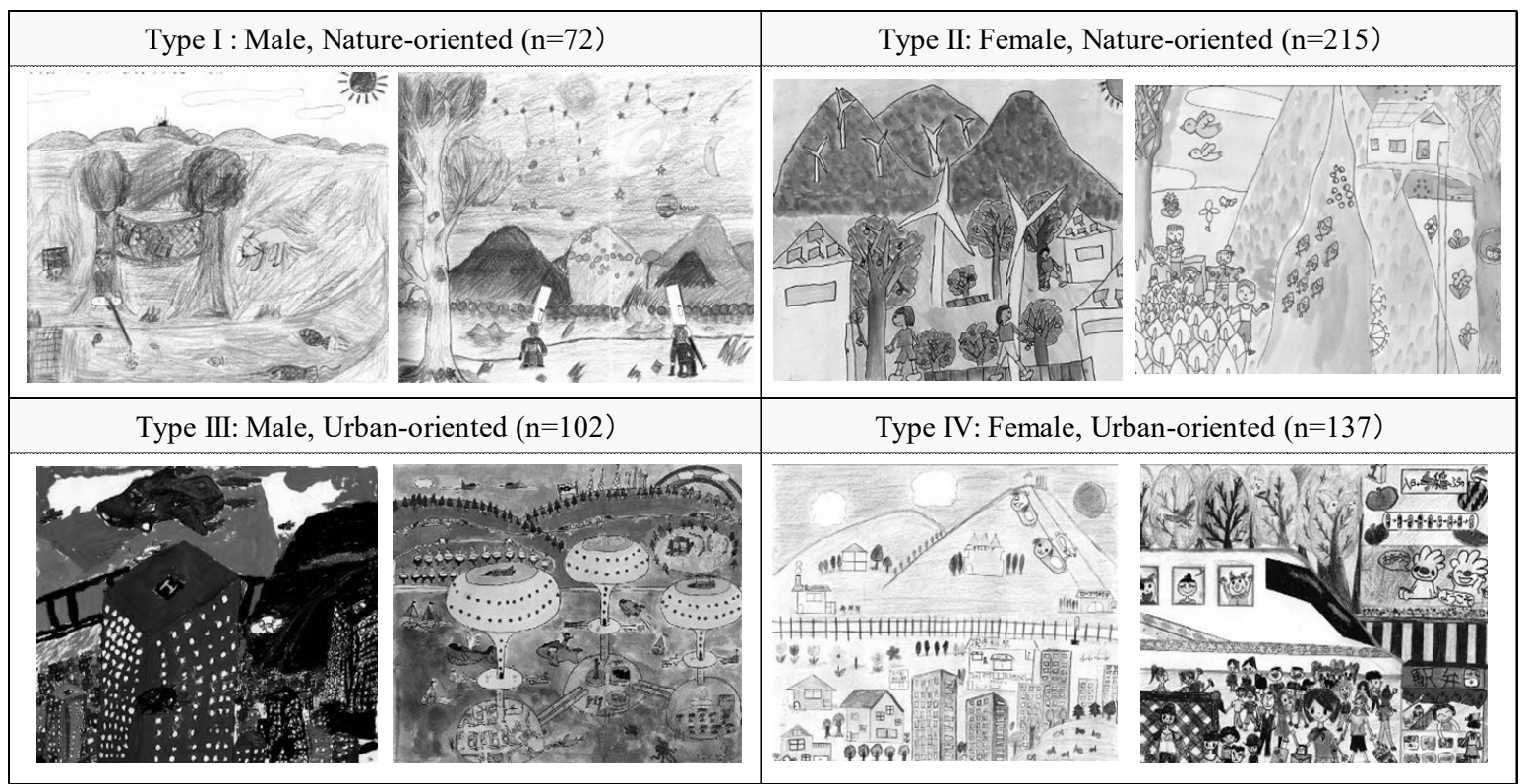

Figure 5. Children's future map drawings of each type 